\title{
Root traits for low input agroecosystems in Africa
}

\author{
Mame Sokhatil Ndoye ${ }^{1}$, Jimmy Burridge ${ }^{2}$, Rahul Bhosale ${ }^{3}$, Alexandre Grondin ${ }^{2}$, and \\ Laurent Laplaze ${ }^{4}$ \\ ${ }^{1}$ CERAAS \\ ${ }^{2}$ Institut de recherche pour le developpement France-Sud \\ ${ }^{3}$ University of Nottingham \\ ${ }^{4}$ Institut de Recherche pour le Développement Centre de Montpellier
}

June 12, 2021

\begin{abstract}
In Africa, agriculture is largely based on low-input and small-holder farming systems that use little inorganic fertilizers and have limited access to irrigation and mechanization in comparison to modern agricultural systems. Improving agricultural practices and developing new cultivars adapted to these low-input environments, where production already suffers from climate change, is a major priority for ensuring food security in the future. Root phenes improving water and nutrient uptake could represent a solution toward achieving these goals. In this review, we illustrate how breeding for specific root phenes could improve crop adaptation and resilience in Africa using three case studies covering very contrasted low-input agro-ecosystems. We conclude with a discussion on how these phenes could be validated and made available to breeders and agronomists.
\end{abstract}

\section{Introduction}

The Green Revolution was driven by the development of novel cultivars along with government subsidised fertilizer inputs, mechanization and irrigation and has dramatically increased crop and farm productivity (Pingali 2012). These changes required massive and coordinated investment across public and private institutions. While most of the world enjoyed significant increase in agricultural productivity, Africa and in particular its sub-Saharan parts, maintained the same degree of productivity (Johnson, Hazell \& Gulati 2003). Recent surveys on agriculture practices in six sub-Saharan countries (Niger, Nigeria, Ethiopia, Malawi, Tanzania and Uganda) covering over 62,000 plots estimated that only 1 to $3 \%$ of the lands cultivated by smallholders are irrigated and no more than $10 \%$ of the households have water control on their field (Sheahan \& Barrett 2017). For instance, $41 \%$ in Nigeria, $17 \%$ in Niger and $3.2 \%$ in Uganda of the cultivated plots used inorganic fertilizer, while $84 \%$ of the total studied area did not use agro-chemicals (pesticides, herbicides, fungicides and insecticides; Sheahan \& Barrett 2017). Although policy makers and donors are supporting efforts to stimulate a Green Revolution in Africa, it is unlikely that it will take the same forms of the first one because of the limited irrigated land and fertilizer resources (phosphorous $(\mathrm{P})$ in particular) exacerbated by climate change and soil degradation (Bailey-Serres, Parker, Ainsworth, Oldroyd \& Schroeder 2019; Gionfriddo, De Gara \& Loreto 2019).

In Africa, efforts to deal with low fertility soils are restricted by the challenges associated with transporting and applying massive amounts of material to dispersed and inaccessible farms. In contrast, improving agricultural practices and developing new cultivars of key food crops can have a substantial impact on food security, income production and agro-ecosystem dynamics while minimizing expenditure (Lynch 2007; Fess, Kotcon \& Benedito 2011; Gemenet et al. 2016; Joshi et al.2016). For this, identification of useful phenes ("phene" is to phenotype and "gene" is to genotype; York, Nord \& Lynch 2013) and phene combinations 
useful for crops grown in low-input agroecosystems and their integration into breeding programs is of major importance. Foremost among the challenges is developing and deploying phenotyping tools in these environments, understanding GxE interactions and generating truly integrative phenotyping and selection approaches that ultimately increase yield and small-holder incomes (Reynolds et al. 2021).

Root architectural and anatomical phenes that increase the efficient acquisition of soil resources, as defined by carbon investment per resource gained, are potentially valuable selection targets. These traits can improve crop tolerance to the main primary constraints in the low-input agroecosystems of Africa, namely water and phosphorus scarcity (extensively reviewed in Lynch 2018, 2019; Schneider \& Lynch 2020). However, tradeoffs for specific traits have been identified due to the contrasting spatial and temporal dynamics of these two resources. For example, shallow root growth promotes topsoil foraging and $\mathrm{P}$ acquisition, while deep root growth promotes subsoil foraging and water acquisition (Ho, Rosas, Brown \& Lynch 2005; Lynch 2011). Root ideotypes (target root phenotypes) for agroecosystems in Africa also need to consider agricultural practices. The implementation of new sustainable approaches for water saving and promotion of soil fertility through the use of beneficial root-soil microorganisms interactions is another potentially fruitful option.

In this review, we will illustrate how breeding for root traits could improve crop adaptation and resilience in low-input African agroecosystems subject to climate change using three case studies. We then discuss how these traits and innovations could be validated, made available to breeders and agronomists and finally adopted by farmers.

\section{Case study 1: improving phosphorus acquisition efficiency in common bean in South East Africa}

Common bean (Phaseolus vulgaris ) has critical food security, economic and agroecosystem value throughout South East Africa (Wortmann, Kirkby, Eledu \& Allen 1998; Beebe 2012). It is fundamental for food security at the household level, as well as economically important at the household, village and regional level. Furthermore, common bean has a key agroecosystem role as a nitrogen (N) fixer. Bean in South East Africa is grown either as a sole crop or intercropped with maize, in both cases usually in rotation with the latter. The primary constraints to production in typical low-input small-holder and low-external input cropping systems in SE Africa include a) low phosphorus (P) availability in highly $\mathrm{N}$ fixing soils, b) terminal and/or intermittent drought, and c) limited root growth and elevated root mortality due to acid soil complexes, pathogens and insects (Lynch 2019). These challenges are further complicated by irrigation systems, fertilizers and other soil amendments being inaccessible due to cost and transportation limitations.

In Mozambique, researchers from the Mozambican Agricultural Research Institute (IIAM) along with collaborators at the International Centre for Tropical Agriculture (CIAT) and The Pennsylvania State University targeted root traits to develop novel varieties that substantially improved small-holder crop production and benefits to local agroecosystems. In this context, increasing $\mathrm{P}$ acquisition efficiency, defined by the ratio of carbon investment to $\mathrm{P}$ recovered, was identified as a key cross-cutting element because it impacts multiple aspects of plant productivity and agroecosystem function (Lynch \& Ho 2005). For instance, shallow root growth has an advantage for the acquisition of soil resources with greater availability in shallow soil zones, particularly P. Greater P acquisition is in turn related to increased shoot growth, biological nitrogen fixation and yield. With a larger shoot biomass shielding the soil, erosion is also reduced (Henry, Kleinman \& Lynch 2009; Henry, Chaves, Kleinman \& Lynch 2010).

Towards breeding of novel common beans for $\mathrm{P}$ acquisition efficiency in Mozambique, greater basal root whorl number and longer and denser root hairs traits were specifically targeted. These traits affect the zone of soil explored (Fig. 1a), they can be easily and rapidly phenotyped in the field with resources readily available in less developed countries (Burridge, Jochua, Bucksch \& Lynch 2016), modifications of these traits do not require any change to the cropping system or farmer practices, and they have multi-scale impact. Basal roots are a class of roots specific to dicots with epigeal germination and emerge from the transition zone between radicle and hypocotyl (Burridge, Rangarajan \& Lynch 2020). In common bean, basal roots emerge in whorls composed of four individual roots, due to its tetrarch vascular patterning (Fig. 1b; Miguel, 
Widrig, Vieira, Brown \& Lynch 2013). Basal root whorl number (BRWN) is under genetic control and ranges from one to five, with two being the mode (Miguel et al. 2013). It can be phenotyped using low cost root roll-ups five to nine days after germination (Fig. 1b) and is associated with field phenotypes and field performance (Strock et al. 2019; Jochua, Strock \& Lynch 2020). Greater BRWN increases the vertical zone of soil explored, enabling the efficient exploration of both deep and shallow soil. It may also afford a degree of root redundancy that ensures at least a few roots will survive pathogen or insect attack to contribute to both deep and shallow resource acquisition (Strock et al. 2019).

Root hairs are subcellular protrusions emerging from specialized epidermal cells on all root classes (Bhosale et al. 2018). Root hair length and density are under genetic control and have been related to greater $\mathrm{P}$ acquisition in multiple crops and experimental systems (Ma, Walk, Marcus \& Lynch 2001; Yan, Liao, Beebe, Blair \& Lynch 2004; Hanlon et al. 2018). Root hairs have minimal construction and maintenance costs making them an extremely efficient means to increase root volume and acquire immobile soil resources such as P (Lynch 2019). They are relatively easy to phenotype at the seedling stage using a low-cost root roll-up protocol (Vieira, Jochua \& Lynch 2007). Substantial synergy between greater root hairs and basal root growth angle have been observed in common bean in which the advantage of longer and denser root hairs is magnified when paired with shallow basal root growth (Miguel, Postma \& Lynch 2015). Taken together, the shallower basal root growth angle and longer and increased density of root hairs traits makes ideal selection targets for improving $\mathrm{P}$ acquisition efficiency (Fig 2A).

The selection strategy for improved $\mathrm{P}$ acquisition efficiency varieties involved extensive phenotyping of varieties and breeding lines in order to identify accessions possessing high BRWN as well as long and dense root hairs (Burridgeet al. 2019). These superior lines were then crossed with common varieties either already grown in Mozambique or to varieties with similar and desirable agronomic and market characteristics, such as seed colour and size. Several early generations of these lines were grown at the experimental stations with non-limiting conditions to select them for adaptation, grain quality, shoot architecture, disease and pest tolerance. Subsequently, seeds from F4 plants were evaluated for key root hair phenes with those possessing longer and denser root hairs being advanced. Targeted field-based selection of varieties took place first on multiple stations across Mozambique with single constraints, such as low soil phosphorus or terminal drought. Simultaneously, selections were made on more remote stations and farmer's fields with multiple, interacting constraints. A final set of 40 varieties were included in a round of on-farm participatory variety selection using a tricot model in which each of many individual farmers received a random pack of three varieties (van Ettenet al. 2019). As a result, three new varieties of common bean, named Kufuna, Tiyela and Matina, have been released in Mozambique. Trials on station and on farmer's field suggests these lines have yields roughly double the yield of local varieties when grown with or without $\mathrm{P}$ fertilizer (Table 1). This is a noteworthy achievement, in part because no new varieties had been released in Mozambique for over 12 years, and none of those were bred specifically for Mozambique.

To further promote and study how new varieties are shared and impact yield, food security and local economies, a pilot promotional campaign was organized in three different regions and compared to three regions that received the improved seed but not the promotional campaign (Fig. 1c\&d). These improved varieties of local adapted and accepted material are available directly from IIAM, as well as from multiple private companies. Stocks of breeder and pre-basic seed are maintained by IIAM and are distributed to companies to produce basic seed. Village level farmer organizations receive pre-basic seeds to produce certified seed lots. In the 2019-2020 season, approximately 11 tons of seed was produced, 6.1 tons of which went to seed companies and the rest to farmers either directly or via various programs, including farmer organizations producing certified seed. In the 2020-2021 season, approximately 45 tons of seed is expected to be produced by IIAM. At typical planting rate of $80 \mathrm{~kg} / \mathrm{ha}, 45$ tons of seed converts to 3,600 hectares of improved P-efficient seed that will be planted by farmers in the 2021-2022 season, up from zero in the 20182019 season. This mixed public, private and farmer organization model promotes the maximum penetration of the new varieties and promotes long-term sustainability for both companies and farmer organizations. Other varieties of common bean are in various stages of the pipeline with some nearly ready for release and others in on-farm trials. 
The accomplishments in Mozambique demonstrate the utility of a selection strategy involving trait-based selection of seedling root phenes, which was followed by on-station trials targeting specific abiotic constraints and soil types and then on-farm trials with multiple biotic and abiotic constraints and the use of local practices. Similar systems have proved successful and continue to offer great potential (Humphrieset al. 2015; Ryan et al. 2018; van Etten et al.2019). Other key legumes, namely cowpea, groundnut and chickpea have very similar food security, economic and agro-ecosystem roles across broad swaths of Africa. Lessons from common bean can be in large applied to these other legumes due to similar root system, phenology as well as seed saving, sharing and buying systems.

\section{Case study 2: Improving water and nutrient acquisition in dryland cereals in West Africa}

Sorghum (Sorghum bicolor [L.] Moench) and pearl millet (Pennisetum glaucum [L.] R. Br.) are the fifth and sixth most important cereal crop in the World (FAOSTAT 2007; FAO 2014). They are well adapted to arid and semi-arid environments found in sub-Saharan Africa and India. In these regions, they are usually grown one cycle a year during the rainy season by smallholder farmers and represent a major source of micronutrient protein for humans and fodder for livestock. They are usually sown at low density (around 10,000 plants per hectare,FAO 2012) before or right after the first rain of the season and grown with no or low inputs simply because water and fertilizers are inaccessible and/or unaffordable (Matlon 1990; vom Brocke et al. 2010). Although sorghum and pearl millet prevail in these environments where other mainstream crops tend to fail, their cultivation is increasingly threatened by high temperature and intermittent drought caused by climate change and soil degradation caused by loss of nutrients and soil organic carbon, a phenomenon accentuated by desertification and erosion (Jones et al. 2013; Sultan, Defrance \& Iizumi 2019). Therefore, improving the resilience of sorghum and pearl millet is particularly important for food security in arid and semi-arid regions of Africa and for adaptation of African agriculture to future climates.

Sorghum and pearl millet root systems are characterized by a single primary root and multiple post-embryonic nodal roots that originate from the mesocotyl (Tsuji et al. 2005; Chopart, Sine, Dao \& Muller 2008; Singh et al. 2010; Faye et al. 2019). Primary, seminal and nodal roots all have lateral roots. In pearl millet, three different types of lateral roots have been identified that differ by length, diameter and internal structures (Passot et al. 2016), as well as by their growth dynamics (Passot et al. 2018). In sorghum, large variability in crown root angle and root area was observed in diversity panels, backcross nested association mapping (BCNAM) populations and recombinant inbred lines (Mace et al. 2012; Joshi et al. 2017). Similarly, diversity in primary root growth and root branching (Passot et al. 2016), and root length density (Faye et al. 2019) was observed in pearl millet. Despite this observed root phenotypic diversity and the fact that several authors have proposed root phenes as breeding targets for improvement of sorghum and pearl millet (Gemenetet al. 2016; Joshi et al. 2016), selection strategies involving root phenes have not been deployed to improve their cultivation so far.

For sorghum and pearl millet grown in sub-Saharan Africa where soils are generally deep and sandy with low water retention, deep rooting might be particularly interesting for tolerance to drought stress (Joshi et al. 2016). In maize, reducing crown root number or lateral root density was associated with deeper root growth, greater water capture at depth and improved plant water status and yield under drought (Zhan, Schneider \& Lynch 2015; Gao \& Lynch 2016). This response is linked to a carbon allocation mechanism in which plants that develop fewer roots are able to invest more carbon in individual roots that can grow deeper (Lynch 2013, 2018; Van Oosterom et al. 2016). Another means for a plant to grow deeper roots is to develop nodal roots with steeper growth angle (Lynch 2013). In sorghum, QTLs for steep nodal root angle co-located with QTL previously identified for stay-green and were associated with grain yield (Mace et al. 2012; Borrell et al. 2014).

Reduced root cortical cell file number (CCFN) and cortical cell size (CCS) were also hypothesized to reduce the metabolic cost of soil exploration (Lynch 2018). Maize lines with lower CCFN and greater CCS showed reduced root respiration, increased root growth at depth, better shoot growth and water status, and significant increase in yield under drought as compared to lines with more CCFN and less CCS (Burton, Brown \& Lynch 2013; Jaramillo, Nord, Chimungu, Brown \& Lynch 2013; Chimungu, Brown \& Lynch 2014a,b). 
Similarly, maize lines with more root cortical aerenchyma (RCA) showed decreased root respiration, increased deep rooting, shoot growth and yield (Zhu, Brown \& Lynch 2010; Chimungu et al. 2015). Moreover, simulations using the functional-structural plant model OpenSimRoot showed that more RCA, less CCFN and lower CCS had beneficial effects on plant biomass after 42 days of growth under nitrogen $(\mathrm{N}), \mathrm{P}$ and potassium (K) stresses (Postma et al. 2017; Lynch 2019). RCA formation was observed both in sorghum and pearl millet indicating that this phene could be explored for diversity, genetic control and used for improving drought tolerance (Promkhambut, Polthanee, Akkasaeng \& Younger 2011; Jaffuel et al. 2016; Passotet al. 2016). No information exists however on CCFN and CCS diversity nor their impacts in sorghum and pearl millet drought response.

If drought tolerance is often dependent on the ability for the plant to capture water, it is equally dependent on the way this water is used to produce biomass, i.e. its transpiration efficiency. Strategies to improve transpiration efficiency have sometimes relied on reduced xylem conductance capacity. In wheat for instance, reduced xylem diameter and the associated reduced root hydraulic conductance resulted in more conservative plants that yielded $11 \%$ more grains under drought conditions (Richards \& Passioura 1989). In fact, annual crop plants adapted to drought stress environments tend to favour smaller xylem diameter as a water conservation strategy (Henry, Cal, Batoto, Torres \& Serraj 2012; Kadam, Yin, Bindraban, Struik \& Jagadish 2015; Grondin, Mauleon, Vadez \& Henry 2016). Sorghum lines with higher number of xylem vessels showed higher transpiration rate which suggest that reducing xylem vessel number in this crop could lead to water saving strategies (Salih et al. 1999). The ability for a plant to restrict transpiration when the vapor pressure deficit (VPD) is above a certain threshold (transpiration restriction) represents other means for improving transpiration efficiency (Sinclairet al. 2017). In sorghum, simulations suggested that restricting maximum transpiration would increase transpiration efficiency and sustain physiological activities and yield (Sinclair 2005). Large variability for this transpiration restriction phenotype was observed in sorghum and in pearl millet (Kholová et al. 2010; Reddy et al. 2017; Tharanya et al. 2018; Karthika et al. 2019). In pearl millet, transpiration restriction was recently linked with root and shoot aquaporins expression although their precise function in this mechanism remains largely unknown (Reddy et al. 2017; for review see Shekoofa \& Sinclair 2018; Tharanya et al. 2018). Improving transpiration efficiency (biomass/water transpired) over the entire crop cycle, possibly by restricting maximum transpiration at high VPD through reduction in root xylem size and possibly modulation in aquaporin functions could well conserve soil water for the critical reproduction and grain filling stage (Kholová et al. 2010; Vadez, Kholová, Yadav \& Hash 2013; Vadez 2014).

Root hairs are well-known to improve $\mathrm{P}$ acquisition from the soil by increasing the absorption area of the root system (Lynch 2019). In sorghum and pearl millet, characterization of root hair density and length, genotypic variation, as well as their role in $\mathrm{P}$ uptake, remains limited. Recent study of the genetic architecture of phosphorus efficiency in sorghum showed colocalization between QTL for P acquisition efficiency, grain yield, surface area and root diameter (Bernadino et al., 2019). Interestingly, one QTL located on chromosome 3 was in close physical proximity with the sorghum homolog of rice serine/threonine kinase OsPSTOL1, which was previously found to enhance early root growth and grain yield in rice under low-P (Gamuyao et al. 2012; Bernardino et al. 2019). Increasing exploration of shallow soil by increasing root length density or by increasing root hair length and density might be beneficial for $\mathrm{P}$ capture. In addition, benefits from more root hairs of sorghum could come from their contribution to the synthesis and exudation of sorgoleone that have demonstrated roles in growth inhibition of weeds (Netzly \& Butler 1986; Pan et al. 2018).

There are clear trade-offs between root phenes beneficial for drought and low-P tolerance. In environments where $\mathrm{P}$ scarcity is always a constraint but drought is often intermittent, increased top-soil root hair length and density combined with drought-inducible plasticity in deeper root growth possibly through reduced topsoil root carbon cost (more RCA for instance) could co-optimize drought and low-P tolerance (Fig. 2B). Drought-related root plastic response has been described inSetaria italica (a close relative of sorghum and pearl millet), where an interruption in crown root growth under drought was observed (Sebastianet al. 2016). This plastic response appeared to be conserved in sorghum and pearl millet where nodal root length was significantly reduced when grown in split-pot system where the seminal root grew in moist soil while the crown roots grew in dry soil (Rostamza, Richards \& Watt 2013). These observations suggest that root plasticity 
in response to drought exists, and could be exploited to improve drought-tolerance. Intercropping systems where root systems of neighbouring plants (sorghum/pearl millet and cowpea/groundnut for instance) could have complementary interactions in terms of water and nutrient availability without competing with each other may also help reducing these trade-offs (Brooker et al. 2015).

Beyond root architectural and anatomical phenes, targeting the rhizosphere could be another future avenue to improve dryland cereals performance (de la Fuente Cantó et al. 2020). The rhizosphere is the volume of soil around the root under the influence of the root system, i.e. whose physico-chemical and biological properties are modified by the root, which, in turn, impacts plant nutrition, development and physiology (York, Carminati, Mooney, Ritz \& Bennett 2016; de la Fuente Cantó et al. 2020). One potential rhizosphere target phene in sorghum and pearl millet would be rhizosheath formation, i.e. the aggregation of soil particles around the roots (Ndour, Heulin, Achouak, Laplaze \& Cournac 2020). This fraction of the soil firmly attached to the roots corresponds to the most biologically active fraction of the rhizosphere. First described in desert grasses, rhizosheath formation has since been reported in many cereal crops including sorghum and pearl millet (Duell \& Peacock 1985; Brown, George, Neugebauer \& White 2017; Ndour et al.2017b). A positive impact on water and mineral nutrition was reported for several plants in laboratory conditions and could be in part explained by improved contact between the soil and the root surface (Ndour et al. 2020). Phenotyping for rhizosheath size is high throughput and this phene is largely under plant genetic control and large variability exists in the germplasm in pearl millet thus making it a potential target for breeding (Ndour et al. 2021). However, further work is needed to demonstrate the impact of a larger rhizosheath on dryland cereals in field conditions.

\section{Case study 3: Water-saving rice agro-ecosystems for West Africa}

Rice is the most consumed cereal in West-Africa and its demand is strongly increasing mostly due to population growth and changes in consumption pattern linked to increased urbanization (Elbehri, Kaminski, Koroma, Iafrate \& Benali 2013; ECOWAS 2019). Currently, local production covers only roughly $60 \%$ of the demand, the rest of the populations' needs being met through imports that strongly impact the region's economy and make it vulnerable to changes in prices on the global commodity market (ECOWAS 2019). Since a majority of West Africans are projected to live in urban areas in the future, demand for rice is expected to increase further by 73.5 percent from 2011 to 2025 (Elbehri et al. 2013; ECOWAS 2019). Several programs have been launched to increase local production to meet this future demand and guarantee food sovereignty.

However, irrigated rice cultivation requires a large amount of freshwater. It was estimated that, in a dry environment with an evaporation rate higher than the precipitation rate found in large parts of West Africa, traditional irrigated rice cultivation requires between 700 to $1,500 \mathrm{~mm}$ of water to produce $1 \mathrm{~kg}$ of rice (Bhuiyan 1992). Furthermore, climate change is trending towards hotter and dryer atmosphere prevailing in the region, which will increase evaporative demand. With increased competition from industries and city growth for freshwater and increased uncertainty in precipitation patterns resulting in reduced water availability in the region, it will not be possible to meet the growing demand with local rice production using the conventional irrigated rice cultivation system (Nie et al. 2012). Several water-saving alternatives have been suggested including alternate wetting and drying (AWD) or aerobic cultivation in order to reduce water consumption and increase cultivated surfaces. While these practices can save up to $50 \%$ of the water used for rice production, they often incur a yield penalty with the current varieties that have been selected for irrigated agro-ecosystems (Bouman, Peng, Castañeda \& Visperas 2005; Peng et al. 2006; Kreye et al.2009; Sasaki et al. 2010).

Aerobic rice cultivation aims to maximize crop water use efficiency by growing plants in soil without flooding or puddling (Matsunami, Matsunami \& Kokubun 2009; Matsuo \& Mochizuki 2009). It allows greater water savings and can be deployed in regions without access to irrigation water but has a high yield penalty and is associated with increased weed management and risks of nematodes. In this system, periodic drought stress may reduce yield stability and yield potential (Sandhu et al. 2019). For these reasons, aerobic rice has not become popular among farmers in irrigated areas (Meena, Bhusal, Kumar, Jain \& Jain 2019). On the 
other hand, AWD is a simple practice where, instead of keeping the fields permanently flooded, irrigation is periodically stopped until the soil water table reaches a certain depth, easily measured using a pipe set in the soil, and then re-started until the field is flooded again (Bouman \& Tuong 2001). AWD cycles are repeated either during the vegetative or flowering stage or throughout the rice cultivation cycle, although keeping paddies flooded in hot environments during the flowering stage help avoid the problems linked to heat sensitivity though the cooling effect of transpiration (Jagadish, Murty \& Quick 2015). Two types of AWD have been described: moderate AWD when field water level is allowed to drop down to $15 \mathrm{~cm}$ below the soil surface, and severe AWD when soils are allowed to dry beyond $-20 \mathrm{kPa}$ (Carrijo et al. 2017). AWD can be easily adopted in these areas as it does not change the cultivation practices, is not associated with increased labour needs and can contribute to a reduction in water consumption of 5 to $30 \%$, depending on the season and soil, as well as reduce methane emissions and grain arsenic levels (Linquistet al. 2015; Carrijo, Lundy \& Linquist 2017).In general, AWD has a limited yield penalty (5.4\% in a meta-analysis of 56 studies) but the yield decrease is more important in severe AWD or if AWD is maintained throughout the crop cycle (Carrijo et al. 2017). The impact on yield is also very dependent on the genotype and most of the currently used high-yield varieties show yield reduction in AWD (Carrijoet al. 2017; Sandhu et al. 2017). Thus, there is a clear need to develop new varieties to optimize yield in AWD rice agroecosystems.

The use of root traits has been little explored in such agroecosystems, but could have a large impact to optimize Water Use Efficiency (WUE), P use efficiency (PUE) and N use efficiency (NUE) and thus reducing inputs globally in AWD systems. Indeed, AWD results in periodic changes in water content in the topsoil but also changes the dynamics of nutrient availability and in particular of $\mathrm{N}$ and $\mathrm{P}$ availability (Wang et al. 2016; Acosta-Motos et al. 2020). For instance, AWD increases topsoil P availability and has been linked with changes in the soil microbiota and the stimulation of aerobic P-solubilizing bacteria in the aerobic topsoil compartment ( $\mathrm{Li}$ et al.2018). Conversely, $\mathrm{N}$ availability seemingly decreases upon AWD due to increased denitrification, volatilisation and leaching although these losses can be avoided by timely $\mathrm{N}$ application (Tan et al. 2013; Djaman et al. 2018). Water and $\mathrm{N}$ signalling are known to interact in ways that affect root phenes for synergistic or antagonistic resource uptake (reviewed in Araus, Swift, Alvarez, Henry \& Coruzzi 2020). Hence, varieties for AWD agro-ecosystems need to be adapted to fluctuations in soil water and nutrient content in the topsoil. Root phenes could be mobilized to that end as a large genetic diversity for these phenes is available in rice (Ahmadi et al. 2014). Interestingly, AWD seems to have a positive effect on root development as indicated by increased root biomass and maximum root length (Wanget al. 2016; Acosta-Motos et al. 2020).

Root phenes that increase the volume of topsoil exploration and promote $\mathrm{P}$ uptake should be prioritized to improve rice yields in AWD systems. Phenes that merit investigation include crown root number, lateral root density (there are two types of lateral roots in rice, thin and determinate short lateral roots and indeterminate long lateral roots; Rebouillatet al. 2009), and root hair length and density. A recent large-scale study by Sandhu et al. (2017) is consistent with nodal root number and lateral root density positively impacting yield in AWD. Evaluation of new rice varieties derived from crosses between popular varieties and droughttolerant accessions was performed in fully-irrigated and AWD systems in seven sites across Asia (Sandhu et al. 2017). Out of 82 lines tested in at least three sites, lines with stable and high yield in AWD conditions compared to irrigated conditions were identified. Comparison of the root phenotype of a subset of these stable high-yielding lines and the control line IR64 (high yield variety that shows a reduction in yield in AWD) showed that higher nodal root number and root dry weight at 10-20 cm depth played an important role in maintaining grain yield under AWD (Sandhu et al. 2017). Interestingly, quantitative changes in these root phenes induced after initiation of AWD cycle, i.e. plasticity response of the root system, were shown to be important for yield stability (Sandhu et al. 2017). These observations are in agreement with previous analyses describing the important role of root system plasticity for drought and low $\mathrm{P}$ tolerance in field and controlled conditions (Sandhu et al. 2016). In the best performing lines under AWD (initially selected as drought tolerant breeding lines), the number of nodal roots below $20 \mathrm{~cm}$ and deep root length at the flowering stage appear to have a positive effect on yield (Sandhu et al. 2017). Therefore, these lines may have had the ability to grow roots in deeper soil layers for improved water and nitrogen acquisition in the 
dry down period (particularly at flowering stage in severe AWD scenario and less so when the water table is maintained above 15-30 cm), while AWD-induced root branching plasticity in the topsoil improved $\mathrm{P}$ uptake (Fig. 2C). Moreover, a study performed using a combination of pot experiments and functional-structural plant model indicated that, for $\mathrm{P}$ uptake, root system efficiency is improved by increased root branching both in irrigated and water stress conditions (De Bauw et al. 2020). In AWD, phosphate acquisition was shown to occur mainly at the root tip and led to phosphorus depletion along the root due to the low mobility of $\mathrm{P}$ in the soil (De Bauw et al. 2020). Root interactions with soil symbiotic microbes such as arbuscular mycorrhizal fungi (AMF), which is inhibited by flooding, might also improve water and nutrient acquisition in the topsoil (Vallino, Fiorilli \& Bonfante 2014; Mbodj et al. 2018). Furthermore, AMF were shown to confer drought tolerance in rice (Chareesri, De Deyn, Sergeeva, Polthanee \& Kuyper 2020). Interestingly, AMF colonization was also shown to reduce $\mathrm{P}$ loss from paddy fields thus improving PUE and reducing environmental impacts (Zhang et al. 2020). Thus, root phenes that promote AMF infection in topsoil such as increased number of crown roots and large lateral roots with more cortex cells and less aerenchyma to accommodate intracellular fungal structures may lead to improved water and nutrient uptake. Moreover, rice response to AMF infection is dependent on the plant genotype and could be targeted for plant breeding (Diedhiouet al. 2016; Huang et al. 2020; Lefebvre 2020).

Overall, improving root phenes in rice for AWD systems could lead to improved WUE but also PUE (AcostaMotoset al. 2020) and NUE (Wang et al. 2016) through synergistic interactions between water and nutrients, thus leading to more sustainable rice agro-ecosystems with reduced water and fertilizer consumption. Lines adapted to aerobic conditions that show root plasticity in response to AWD in topsoil (increased branching) could be interesting materials to test. Rhizosphere phenes could also be targeted to improve water and nutrient acquisition efficiency in this system.

\section{Conclusion}

We propose two main root phene-based strategies to accelerate the development of new cultivars better adapted to low-input environments in Africa.

The first is to identify simple phenes that have broadest positive influence on enhanced performance and that also minimize trade-offs. Towards this, long and dense root hairs are likely selection criteria as greater root hair length and density promotes exudation and have positive effects on the beneficial microbial activity within the rhizosphere (Rongsawat, Peltier, Boyer, Very \& Sentenac 2021). Additionally, root plasticity phenes could be another potential selection criteria as for topsoil root branching plasticity could be beneficial upon partial dry-down (for rice in AWD agroecosystems) while subsoil root plasticity could be beneficial during prolonged drought stress particularly in the reproduction and grain filling stage (for sorghum and pearl millet in arid and semi-arid agroecosystems).

The second major strategy is to understand and target phene synergisms and integrated phenotypes. Synergisms between root phenes are defined as interactions that have more than additive effect, as in the case of long and dense root hairs paired with shallow root system architecture for $\mathrm{P}$ acquisition (Miguel et al. 2015). Integrated phenotypes would clearly affect the utility of selecting for a single component phene without selecting for their complementary phenotypes. For example, the utility of high conductance capacity xylem likely depends on root phenes that affect rooting depth since deep roots can access and thus transport greater volumes of soil water (Strock, Burridge, Niemiec, Brown \& Lynch 2020). The development of root structural and functional models for crops such as sorghum or pearl millet that can evaluate the effects of architectural and anatomical phenes in changing soil environments and its effects on root functions will be particularly useful (Ndour, Pradal \& Lucas 2017a). Other less well characterized phene assemblages, especially those involving transpiration, should be further investigated and validated in particular stress scenarios (Strock et al. 2019; Klein, Schneider, Perkins, Brown \& Lynch 2020). Considering resource acquisition and use, especially that of water within the context of phenology, leads to acknowledging the importance of interactions among roots and shoots for timely water use across the crop cycle (Vadez, Kholova, Medina, Kakkera \& Anderberg 2014). In that regard, combining root models with crop models could potentially link above-ground phenes to root phenes, the former serving as a proxy for root function (Benes et al. 2020). 
In order to make these innovations readily available to breeders, researchers and breeders need to work together to validate phene utility, develop phenotyping protocols including field sites, the type of genetic material to work with (RILs, NILs, tester lines, germplasm deployment strategy) and ultimately identify marker or genes controlling beneficial phenes. As in the case of common bean presented in case study 1 , identifying a selection strategy, including the type of phene for the appropriate stage, would be particularly useful. To maximize deployment of improved cultivars and to then secure the adoption of those improved cultivars, social scientists and farmers should be integrated in the selection process (Ameleworket al. 2016). The inclusion of useful root phenes in such approaches may help to stimulate a sustainable Green Revolution in Africa.

\section{Acknowledgements}

The authors thank Dr Alain Ghesquiere and Dr Vincent Vadez (IRD) for critical reading of our manuscript. MSN is supported by a PhD grant from the Sorghum and Millet Innovation Lab project (SMIL / Feed the Future) through the United States Agency for International Development (USAID, grant S19182.01). RB is supported by a BBSRC Discovery and Future Food Nottingham Research Fellowships. Work in our labs is supported by the IRD, the French Agence Nationale pour la Recherche (ANR Grant PlastiMil ndegANR20-CE20-0016, ICARUS ndegANR17-MPGA-0011 and RootAdapt ndegANR17-CE20-0022-01), the Royal Society (Anatomics grant ICA $\backslash R 1 \backslash 180356$ ), the Access to Research Infrastructures activity in the Horizon 2020 Programme of the EU (EPPN2020 Grant Agreement 731013) and by the CGIAR Research Programme on Grain Legumes and Dryland Cereals (GLDC).

\section{References}

Acosta-Motos J.R., Rothwell S.A., Massam M.J., Albacete A., Zhang H. \& Dodd I.C. (2020) Alternate wetting and drying irrigation increases water and phosphorus use efficiency independent of substrate phosphorus status of vegetative rice plants. Plant Physiology and Biochemistry155 , 914-926.

Ahmadi N., Audebert A., Bennett M.J., Bishopp A., de Oliveira A., Courtois B., .. Xu J. (2014) The roots of future rice harvests. Rice $7,29$.

Amelework B.A., Shimelis H.A., Tongoona P., Mengistu F., Laing M.D. \& Ayele D.G. (2016) Sorghum production systems and constraints, and coping strategies under drought-prone agro-ecologies of Ethiopia. South African Journal of Plant and Soil 33, 207-217.

Araus V., Swift J., Alvarez J.M., Henry A. \& Coruzzi G.M. (2020) A balancing act: How plants integrate nitrogen and water signals. Journal of Experimental Botany 71 , 4442-4451.

Bailey-Serres J., Parker J.E., Ainsworth E.A., Oldroyd G.E.D. \& Schroeder J.I. (2019) Genetic strategies for improving crop yields. Nature 575, 109-118.

Bandyopadhyay P.K., Singh K.C., Mondal K., Nath R., Ghosh P.K., Kumar N., .. Singh S.S. (2016) Effects of stubble length of rice in mitigating soil moisture stress and on yield of lentil (Lens culinaris Medik) in rice-lentil relay crop. Agricultural Water Management173, 91-102.

Bates T.R. \& Lynch J.P. (2001) Root hairs confer a competitive advantage under low phosphorus availability. Plant and Soil236 , 243-250.

De Bauw P., Mai T.H., Schnepf A., Merckx R., Smolders E. \& Vanderborght J. (2020) A functional-structural model of upland rice root systems reveals the importance of laterals and growing root tips for phosphate uptake from wet and dry soils. Annals of Botany 126, 789-806.

Beebe S. (2012) Common bean breeding in the tropics. Plant Breeding Reviews 36 .

Benes B., Guan K., Lang M., Long S.P., Lynch J.P., Marshall-Colon A., ... Turk M.J. (2020) Multiscale computational models can guide experimentation and targeted measurements for crop improvement.Plant Journal 103, 21-31. 
Bernardino K.C., Pastina M.M., Menezes C.B., De Sousa S.M., MacIel L.S., Geraldo Carvalho G.C., ... Magalhaes J. V. (2019) The genetic architecture of phosphorus efficiency in sorghum involves pleiotropic QTL for root morphology and grain yield under low phosphorus availability in the soil. BMC Plant Biology $19,1-15$.

Bhosale R., Giri J., Pandey B.K., Giehl R.F.H., Hartmann A., Traini R., .. Swarup R. (2018) A mechanistic framework for auxin dependent Arabidopsis root hair elongation to low external phosphate. Nature Communications $\mathbf{9}, 1-9$.

Bhuiyan S.I. (1992) Water management in relation to crop production: case study on rice. Outlook on Agriculture 21, 293-299.

Borrell A.K., Mullet J.E., George-Jaeggli B., Van Oosterom E.J., Hammer G.L., Klein P.E. \& Jordan D.R. (2014) Drought adaptation of stay-green sorghum is associated with canopy development, leaf anatomy, root growth, and water uptake. Journal of Experimental Botany65, 6251-6263.

Boudreau M.A. (2013) Diseases in intercropping systems. Annual Review of Phytopathology 51 , 499-519.

Bouman B. a. M. \& Tuong T.P. (2001) Field water mangement to save water and increase its productivity in irrigated lowland rice.Agricultural Water Management 1615 , 1-20.

Bouman B.A.M., Peng S., Castaneda A.R. \& Visperas R.M. (2005) Yield and water use of irrigated tropical aerobic rice systems. Agricultural Water Management 74, 87-105.

vom Brocke K., Trouche G., Weltzien E., Barro-Kondombo C.P., Goze E. \& Chantereau J. (2010) Participatory variety development for sorghum in Burkina Faso: Farmers' selection and farmers' criteria. Field Crops Research 119 , 183-194.

Brooker R.W., Bennett A.E., Cong W.F., Daniell T.J., George T.S., Hallett P.D., ... White P.J. (2015) Improving intercropping: A synthesis of research in agronomy, plant physiology and ecology.New Phytologist 206 .

Brown L.K., George T.S., Neugebauer K. \& White P.J. (2017) The rhizosheath - a potential trait for future agricultural sustainability occurs in orders throughout the angiosperms. Plant and Soil418, 115-128.

Burridge J., Jochua C.N., Bucksch A. \& Lynch J.P. (2016) Legume shovelomics: High-Throughput phenotyping of common bean (Phaseolus vulgaris L.) and cowpea (Vigna unguiculata subsp, unguiculata) root architecture in the field. Field Crops Research 192, 21-32.

Burridge J.D., Findeis J.L., Jochua C.N., Miguel M.A., Mubichi-Kut F.M., Quinhentos M.L., ... Lynch J.P. (2019) A case study on the efficacy of root phenotypic selection for edaphic stress tolerance in low-input agriculture: Common bean breeding in Mozambique. Field Crops Research 244, 107612.

Burridge J.D., Rangarajan H. \& Lynch J.P. (2020) Comparative phenomics of annual grain legume root architecture. Crop Science60 , 2574-2593.

Burton A.L., Brown K.M. \& Lynch J.P. (2013) Phenotypic diversity of root anatomical and architectural traits in Zea species. Crop Science 53, 1042-1055.

Carrijo D.R., Lundy M.E. \& Linquist B.A. (2017) Rice yields and water use under alternate wetting and drying irrigation: A meta-analysis. Field Crops Research 203 , 173-180.

Chareesri A., De Deyn G.B., Sergeeva L., Polthanee A. \& Kuyper T.W. (2020) Increased arbuscular mycorrhizal fungal colonization reduces yield loss of rice (Oryza sativa L.) under drought. Mycorrhiza30 , $315-328$.

Chimungu J.G., Brown K.M. \& Lynch J.P. (2014a) Large root cortical cell size improves drought tolerance in maize (Zea mays L.). Plant Physiology 166 , 2166-2178. 
Chimungu J.G., Brown K.M. \& Lynch J.P. (2014b) Reduced Root Cortical Cell File Number Improves Drought Tolerance in Maize. Plant Physiology 166 , 1943-1955.

Chimungu J.G., Maliro M.F.A., Nalivata P.C., Kanyama-Phiri G., Brown K.M. \& Lynch J.P. (2015) Utility of root cortical aerenchyma under water limited conditions in tropical maize (Zea mays L.). Field Crops Research 171, 86-98.

Chopart J.L., Sine B., Dao A. \& Muller B. (2008) Root orientation of four sorghum cultivars: Application to estimate root length density from root counts in soil profiles. Plant Root 2, 67-75.

Connolly J., Goma H.C. \& Rahim K. (2001) The information content of indicators in intercropping research. Agriculture, Ecosystems and Environment 87, 191-207.

Cook S.M., Khan Z.R. \& Pickett J.A. (2007) The use of push-pull strategies in integrated pest management. Annual Review of Entomology 52, 375-400.

Dai J., Qiu W., Wang N., Wang T., Nakanishi H. \& Zuo Y. (2019) From leguminosae/gramineae intercropping systems to see benefits of intercropping on iron nutrition. Frontiers in Plant Science10 , 1-7.

Diedhiou A.G., Mbaye F.K., Mbodj D., Faye M.N., Pignoly S., Ndoye I., .. Champion A. (2016) Field trials reveal ecotype-specific responses to mycorrhizal inoculation in rice. PLoS ONE11, 1-17.

Djaman K., Mel V., Ametonou F., El-Namaky R., Diallo M. \& Koudahe K. (2018) Effect of Nitrogen Fertilizer Dose and Application Timing on Yield and Nitrogen Use Efficiency of Irrigated Hybrid Rice under Semi-Arid Conditions. Journal of Agricultural Science and Food Research 9, 1-7.

Duell R.W. \& Peacock G.R. (1985) Rhizosheaths on Mesophytic Grasses 1 .Crop Science 25 , 880-883.

Van Duivenbooden N., Pala M., Studer C., Bielders C.L. \& Beukes D.J. (2000) Cropping systems and crop complementarity in dryland agriculture to increase soil water use efficiency: A review. Netherlands Journal of Agricultural Science $48,213-236$.

ECOWAS (2019) Ecowas Commission - Directorate of agriculture and rural development . (ed The ECOWAS Rice Factbook),

Elbehri A., Kaminski J., Koroma S., Iafrate M. \& Benali M. (2013) West Africa staple food systems: An overview of trends and indicators of demand, supply, and competitiveness of staple food value chains. InRebuilding West Africa's food potential, A. Elbehri. (ed FAO/IFAD), pp. 1-42.

van Etten J., de Sousa K., Aguilar A., Barrios M., Coto A., Dell'Acqua M., .. S Steinke J. (2019) Crop variety management for climate adaptation supported by citizen science. Proceedings of the National Academy of Sciences of the United States of America116 , 4194-4199.

FAO (2012) Localized fertilization at crop seeding or microdosing. pp. 1-4.

FAOSTAT (2007) Food and Agriculture Organization of the United Nation.Database. Available at: http://www.fao.org/faostat/en/\#data .

Food and Agriculture Organization of the United Nation [FAO] (2014) FAOSTAT. Database. Available at: http://faostat3.fao.org/browse/Q/*/E .

Faye A., Sine B., Chopart J.-L., Grondin A., Lucas M., Diedhiou A.G., .. L Laplaze L. (2019) Development of a model estimating root length density from root impacts on a soil profile in pearl millet (Pennisetum glaucum (L.) R. Br). Application to measure root system response to water stress in field conditions. Plos One 14, e0214182.

Felix G.F., Scholberg J.M.S., Clermont-Dauphin C., Cournac L. \& Tittonell P. (2018) Enhancing agroecosystem productivity with woody perennials in semi-arid West Africa. A meta-analysis. Agronomy for Sustainable Development $\mathbf{3 8}$. 
Fess T.L., Kotcon J.B. \& Benedito V.A. (2011) Crop breeding for low input agriculture: A sustainable response to feed a growing world population. Sustainability 3, 1742-1772.

Fromm H. (2019) Root plasticity in the pursuit of water. Plants 8 .

Gahoonia T.S. \& Nielsen N.E. (2003) Phosphorus (P) uptake and growth of a root hairless barley mutant (bald root barley, brb) and wild type in low- and high-P soils. Plant, Cell and Environment 26 , 1759-1766.

Gamuyao R., Chin J.H., Pariasca-Tanaka J., Pesaresi P., Catausan S., Dalid C., ... Heuer S. (2012) The protein kinase Pstol1 from traditional rice confers tolerance of phosphorus deficiency.Nature 488, 535-539.

Gao Y. \& Lynch J.P. (2016) Reduced crown root number improves water acquisition under water deficit stress in maize (Zea mays L.): Supplemental material. Journal of Experimental Botany67 , 4545-4557.

Gemenet D.C., Leiser W.L., Beggi F., Herrmann L.H., Vadez V., Rattunde H.F.W., .. Haussmann B.I.G. (2016) Overcoming phosphorus deficiency overcoming phosphorus deficiency in West African pearl millet and sorghum production systems: Promising options for crop improvement.Frontiers in Plant Science $\mathbf{7}$, $1-10$.

Gionfriddo M., De Gara L. \& Loreto F. (2019) Directed Evolution of Plant Processes: Towards a Green (r)Evolution? Trends in Plant Science 24, 999-1007.

Grondin A., Mauleon R., Vadez V. \& Henry A. (2016) Root aquaporins contribute to whole plant water fluxes under drought stress in rice (Oryza sativa L.). Plant, Cell and Environment 39 .

Haling R.E., Brown L.K., Bengough A.G., Young I.M., Hallett P.D., White P.J. \& George T.S. (2013) Root hairs improve root penetration, root-soil contact, and phosphorus acquisition in soils of different strength. Journal of Experimental Botany 64, 3711-3721.

Hanlon M.T., Ray S., Saengwilai P., Luthe D., Lynch J.P. \& Brown K.M. (2018) Buffered delivery of phosphate to Arabidopsis alters responses to low phosphate. Journal of Experimental Botany 69 , 12071219 .

Harris D. \& Natarajan M. (1987) Physiological basis for yield advantage in a sorghum/groundnut intercrop exposed to drought. 2. Plant Temperature, water status, and components of yield. Field Crops Research $17,273-288$.

Henry A., Cal A.J., Batoto T.C., Torres R.O. \& Serraj R. (2012) Root attributes affecting water uptake of rice (Oryza sativa) under drought. Journal of Experimental Botany 63 , 4751-4763.

Henry A., Chaves N.F., Kleinman P.J.A. \& Lynch J.P. (2010) Will nutrient-efficient genotypes mine the soil? Effects of genetic differences in root architecture in common bean (Phaseolus vulgaris L.) on soil phosphorus depletion in a low-input agro-ecosystem in Central America. Field Crops Research 115 , 67-78.

Henry A., Kleinman P.J.A. \& Lynch J.P. (2009) Phosphorus runoff from a phosphorus deficient soil under common bean (Phaseolus vulgaris L.) and soybean (Glycine max L.) genotypes with contrasting root architecture.Plant and Soil 317, 1-16.

Ho M.D., Rosas J.C., Brown K.M. \& Lynch J.P. (2005) Root architectural tradeoffs for water and phosphorus acquisition. Functional Plant Biology $32,737-748$.

Huang R., Li Z., Mao C., Zhang H., Sun Z., Li H., ... Duanmu D. (2020) Natural variation at OsCERK1 regulates arbuscular mycorrhizal symbiosis in rice. New Phytologist 225, 1762-1776.

Humphries S., Rosas J.C., Gomez M., Jimenez J., Sierra F., Gallardo O., . . Barahona M. (2015) Synergies at the interface of farmer-scientist partnerships: Agricultural innovation through participatory research and plant breeding in Honduras. Agriculture and Food Security 4, 1-17. 
Iqbal M.A., Hamid A., Ahmad T., Siddiqui M.H., Hussain I., Ali S., .. Ahmad Z. (2019) Forage sorghumlegumes intercropping: Effect on growth, yields, nutritional quality and economic returns.Bragantia $\mathbf{7 8}$, $82-95$.

Jaffuel S., vom Brocke K., Hamadou T.V.C., Dardou A., Vidal A. \& Trouche G. (2016) Anatomical features of an African sorghum landrace adapted to flooded conditions. Australian Journal of Crop Science10 , 1489-1495.

Jagadish S.V.K., Murty M.V.R. \& Quick W.P. (2015) Rice responses to rising temperatures - challenges, perspectives and future directions.Plant, Cell and Environment 38, 1686-1698.

Jaramillo R.E., Nord E.A., Chimungu J.G., Brown K.M. \& Lynch J.P. (2013) Root cortical burden influences drought tolerance in maize. Annals of Botany 112, 429-437.

Jochua C.N., Strock C.F. \& Lynch J.P. (2020) Root phenotypic diversity in common bean reveals contrasting strategies for soil resource acquisition among gene pools and races. Crop Science 60 , 3261-3277.

Johnson M., Hazell P. \& Gulati A. (2003) The role of intermediate factor markets in Asia's Green Revolution: Lessons for Africa?American Journal of Agricultural Economics 85 , 1211-1216.

Jones A., Breuning-Madsen H., Brossard M., Dampha A., Deckers J., Dewitte O., ... Zougmore R. (2013) Soil Atlas of Africa.ISSN: 1018-5593.

Joshi D., Singh V., van Oosterom E., Mace E., Jordan D. \& Hammer G. (2016) Genetic Manipulation of Root System Architecture to Improve Drought Adaptation in Sorghum. 207-226.

Joshi D.C., Singh V., Hunt C., Mace E., van Oosterom E., Sulman R., .. Hammer G. (2017) Development of a phenotyping platform for high throughput screening of nodal root angle in sorghum. Plant Methods 13 , $1-12$.

Kadam N.N., Yin X., Bindraban P.S., Struik P.C. \& Jagadish K.S.V. (2015) Does Morphological and Anatomical Plasticity during the Vegetative Stage Make Wheat More Tolerant of Water Deficit Stress Than Rice? Plant Physiology 167, 1389-1401.

Karthika G., Kholova J., Alimagham S., Ganesan M., Chadalavada K., Kumari R. \& Vadez V. (2019) Measurement of transpiration restriction under high vapor pressure deficit for sorghum mapping population parents. Plant Physiology Reports $24,74-85$.

Kholova J., Hash C.T., Kumar P.L., Yadav R.S., Kocova M. \& Vadez V. (2010) Terminal drought-tolerant pearl millet [Pennisetum glaucum (L.) R. Br.] have high leaf ABA and limit transpiration at high vapour pressure deficit. Journal of experimental botany $61,1431-40$.

Klein S.P., Schneider H.M., Perkins A.C., Brown K.M. \& Lynch J.P. (2020) Multiple integrated root phenotypes are associated with improved drought tolerance. Plant Physiology 183 , 1011-1025.

Kreye C., Bouman B.A.M., Reversat G., Fernandez L., Vera Cruz C., Elazegui F., .. Llorca L. (2009) Biotic and abiotic causes of yield failure in tropical aerobic rice. Field Crops Research112, 97-106.

de la Fuente Canto C., Simonin M., King E., Moulin L., Bennett M.J., Castrillo G. \& Laplaze L. (2020) An extended root phenotype: the rhizosphere, its formation and impacts on plant fitness. Plant Journal 103, 951-964.

Lefebvre B. (2020) An opportunity to breed rice for improved benefits from the

FAO (2012) Localized fertilization at crop seeding or microdosing. pp. 1-4.

FAOSTAT (2007) Food and Agriculture Organization of the United Nation.Database. Available at: http://www.fao.org/faostat/en/\#data . 
Food and Agriculture Organization of the United Nation [FAO] (2014) FAOSTAT. Database. Available at : http://faostat3.fao.org/browse $/ Q /{ }^{*} / E$.

arbuscular mycorrhizal symbiosis? New Phytologist 225 , 1404-1406.

Li Z., Li Z., Letuma P., Zhao H., Zhang Z., Lin W., .. . Lin W. (2018) A positive response of rice rhizosphere to alternate moderate wetting and drying irrigation at grain filling stage. Agricultural Water Management $207,26-36$.

Linquist B.A., Anders M.M., Adviento-Borbe M.A.A., Chaney R.L., Nalley L.L., da Rosa E.F.F. \& van Kessel C. (2015) Reducing greenhouse gas emissions, water use, and grain arsenic levels in rice systems. Global Change Biology 21 , 407-417.

Lithourgidis A.S., Dordas C.A., Damalas C.A. \& Vlachostergios D.N. (2011) Annual intercrops: An alternative pathway for sustainable agriculture. Australian Journal of Crop Science 5 , 396-410.

Lynch J.P. (2007) Turner review no. 14. Roots of the second green revolution. Australian Journal of Botany 55, $493-512$.

Lynch J.P. (2011) Root phenes for enhanced soil exploration and phosphorus acquisition: Tools for future crops. Plant Physiology156 , 1041-1049.

Lynch J.P. (2013) Steep, cheap and deep: An ideotype to optimize water and N acquisition by maize root systems. Annals of Botany 112, 347-357.

Lynch J.P. (2018) Rightsizing root phenotypes for drought resistance. Journal of Experimental Botany 69 , 3279-3292.

Lynch J.P. (2019) Root phenotypes for improved nutrient capture: an underexploited opportunity for global agriculture .

Lynch J.P. \& Ho M.D. (2005) Rhizoeconomics: Carbon costs of phosphorus acquisition. Plant and Soil 269 , $45-56$.

Ma Z., Walk T.C., Marcus A. \& Lynch J.P. (2001) Morphological synergism in root hair length, density, initiation and geometry for phosphorus acquisition in Arabidopsis thaliana: A modeling approach. Plant and Soil 236 , 221-235.

Mace E.S., Singh V., van Oosterom E.J., Hammer G.L., Hunt C.H. \& Jordan D.R. (2012) QTL for nodal root angle in sorghum (Sorghum bicolor L. Moench) co-locate with QTL for traits associated with drought adaptation. Theoretical and Applied Genetics 124, 97-109.

Matlon P.J. (1990) Improving productivity in sorghum and pearl millet in semi-arid Africa. Food Research Institute Studies $\mathbf{2 2}$.

Matsunami M., Matsunami T. \& Kokubun M. (2009) Growth and yield of new rice for africa (NERICAs) under different ecosystems and nitrogen levels. Plant Production Science 12 , 381-389.

Matsuo N. \& Mochizuki T. (2009) Growth and yield of six rice cultivars under three water-saving cultivations. Plant Production Science12, 514-525.

Mbodj D., Effa-Effa B., Kane A., Manneh B., Gantet P., Laplaze L., .. G Grondin A. (2018) Arbuscular mycorrhizal symbiosis in rice: Establishment, environmental control and impact on plant growth and resistance to abiotic stresses. Rhizosphere $\mathbf{8}, 12-26$.

Meena R.K., Bhusal N., Kumar K., Jain R. \& Jain S. (2019) Intervention of molecular breeding in water saving rice production system: aerobic rice. 3 Biotech $\mathbf{9}, 1-12$.

Miguel M.A., Postma J.A. \& Lynch J.P. (2015) Phene synergism between root hair length and basal root growth angle for phosphorus Acquisition.Plant Physiology 167 , 1430-1439. 
Miguel M.A., Widrig A., Vieira R.F., Brown K.M. \& Lynch J.P. (2013) Basal root whorl number: A modulator of phosphorus acquisition in common bean (Phaseolus vulgaris). Annals of Botany 112, 973982.

Ndour A., Pradal C. \& Lucas M. (2017a) Virtual Plants Need Water Too : Functional-Structural Root System Models in the Context of Drought Tolerance Breeding. 8 , 1-21.

Ndour P.M.S., Barry C.M., Tine D., De la Fuente Canto C., Gueye M., Barakat M., .. Cournac L. (2021) Pearl millet genotype impacts microbial diversity and enzymatic activities in relation to root-adhering soil aggregation. Plant and Soil .

Ndour P.M.S., Gueye M., Barakat M., Ortet P., Bertrand-Huleux M., Pablo A.-L., .. Cournac L. (2017b) Pearl Millet Genetic Traits Shape Rhizobacterial Diversity and Modulate Rhizosphere Aggregation.Frontiers in Plant Science $\mathbf{8}, 1-14$.

Ndour P.M.S., Heulin T., Achouak W., Laplaze L. \& Cournac L. (2020) The rhizosheath: from desert plants adaptation to crop breeding. Plant and Soil 456, 1-13.

Nelson W.C.D., Hoffmann M.P., Vadez V., Roetter R.P. \& Whitbread A.M. (2018) Testing pearl millet and cowpea intercropping systems under high temperatures. Field Crops Research 217 , 150-166.

Netzly D.H. \& Butler L.G. (1986) Roots of Sorghum Exude Hydrophobic Droplets Containing Biologically Active Components 1. Crop Science 26 , 775-778.

Nie L., Peng S., Chen M., Shah F., Huang J., Cui K. \& Xiang J. (2012) Aerobic rice for water-saving agriculture. A review. Agronomy for Sustainable Development 32, 411-418.

Van Oosterom E.J., Yang Z., Zhang F., Deifel K.S., Cooper M., Messina C.D. \& Hammer G.L. (2016) Hybrid variation for root system efficiency in maize: Potential links to drought adaptation. Functional Plant Biology $43,502-511$.

Pan Z., Baerson S.R., Wang M., Bajsa-Hirschel J., Rimando A.M., Wang X., .. Duke S.O. (2018) A cytochrome P450 CYP71 enzyme expressed in Sorghum bicolor root hair cells participates in the biosynthesis of the benzoquinone allelochemical sorgoleone. New Phytologist218, 616-629.

Passot S., Gnacko F., Moukouanga D., Lucas M., Guyomarc'h S., Ortega B.M., .. L Laplaze L. (2016) Characterization of Pearl Millet Root Architecture and Anatomy Reveals Three Types of Lateral Roots.Frontiers in plant science $\mathbf{7}, 829$.

Passot S., Moreno-Ortega B., Moukouanga D., Balsera C., Guyomarc'h S., Lucas M., .. Guedon Y. (2018) A new phenotyping pipeline reveals three types of lateral roots and a random branching pattern in two cereals. Plant Physiology 177, 896-910.

Peng S., Bouman B., Visperas R.M., Castaneda A., Nie L. \& Park H.K. (2006) Comparison between aerobic and flooded rice in the tropics: Agronomic performance in an eight-season experiment. Field Crops Research $96,252-259$.

Pingali P.L. (2012) Green Revolution: Impacts, limits, and the path ahead. Proceedings of the National Academy of Sciences $\mathbf{1 0 9}$, 12302-12308.

Postma J.A., Kuppe C., Owen M.R., Mellor N., Griffiths M., Bennett M.J., .. Watt M. (2017) OpenSimRoot: widening the scope and application of root architectural models. New Phytologist 215 , 1274-1286.

Postma J.A. \& Lynch J.P. (2012) Complementarity in root architecture for nutrient uptake in ancient maize/bean and maize/bean/squash polycultures. Annals of botany 110, 521-534.

Prieto I., Armas C. \& Pugnaire F.I. (2012) Water release through plant roots: New insights into its consequences at the plant and ecosystem level. New Phytologist 193 , 830-841. 
Promkhambut A., Polthanee A., Akkasaeng C. \& Younger A. (2011) Growth, yield and aerenchyma formation of sweet and multipurpose sorghum (Sorghum bicolor L. Moench) as affected by flooding at different growth stages. Australian Journal of Crop Science 5 , 954-965.

Ratnadass A., Fernandes P., Avelino J. \& Habib R. (2012) Plant species diversity for sustainable management of crop pests and diseases in agroecosystems: A review. Agronomy for Sustainable Development 32 .

Rebouillat J., Dievart A., Verdeil J.L., Escoute J., Giese G., Breitler J.C., .. Perin C. (2009) Molecular genetics of rice root development. Rice $\mathbf{2}, 15-34$.

Reddy P.S., Tharanya M., Sivasakthi K., Srikanth M., Hash C.T., Kholova J., .. . Vadez V. (2017) Molecular cloning and expression analysis of Aquaporin genes in pearl millet [Pennisetum glaucum (L) R. Br.] genotypes contrasting in their transpiration response to high vapour pressure deficits. Plant Science 265 , 167-176.

Reynolds M., Atkin O.K., Bennett M., Cooper M., Dodd I.C., Foulkes M.J., .. Wittich P.E. (2021) Addressing Research Bottlenecks to Crop Productivity. Trends in plant science 26 , 607-630.

Richards R.A. \& Passioura J.B. (1989) A breeding program to reduce the diameter of the major xylem vessel in the seminal roots of wheat and its effect on grain yield in rain-fed environments. Australian Journal of Agricultural Research 40 , 943-950.

Rongsawat T., Peltier J.B., Boyer J.C., Very A.A. \& Sentenac H. (2021) Looking for Root Hairs to Overcome Poor Soils. Trends in Plant Science 26 , 83-94.

Rostamza M., Richards R.A. \& Watt M. (2013) Response of millet and sorghum to a varying water supply around the primary and nodal roots. Annals of Botany 112, 439-446.

Ryan S.F., Adamson N.L., Aktipis A., Andersen L.K., Austin R., Barnes L., .. Dunn R.R. (2018) The role of citizen science in addressing grand challenges in food and agriculture research. Proceedings of the Royal Society B: Biological Sciences $\mathbf{2 8 5}$.

Salih A.A., Ali I.A., Lux A., Luxova M., Cohen Y., Sugimoto Y. \& Inanaga S. (1999) Rooting, water uptake, and xylem structure adaptation to drought of two sorghum cultivars. Crop Science 39, 168-173.

Sandhu N., Dixit S., Swamy B.P.M., Raman A., Kumar S., Singh S.P., .. Kumar A. (2019) Marker Assisted Breeding to Develop Multiple Stress Tolerant Varieties for Flood and Drought Prone Areas. Rice12 .

Sandhu N., Raman K.A., Torres R.O., Audebert A., Dardou A., Kumar A. \& Henry A. (2016) Rice root architectural plasticity traits and genetic regions for adaptability to variable cultivation and stress conditions.Plant Physiology, pp.00705.2016.

Sandhu N., Subedi S.R., Yadaw R.B., Chaudhary B., Prasai H., Iftekharuddaula K., .. Kumar A. (2017) Root traits enhancing rice grain yield under alternate wetting and drying condition. Frontiers in Plant Science 31,1879 .

Sasaki Y., Hosen Y., Peng S., Nie L., Rodriguez R., Agbisit R., .. Bouman B.A.M. (2010) Do abiotic factors cause a gradual yield decline under continuous aerobic rice cultivation? A pot experiment with affected field soils. Soil Science and Plant Nutrition56 , 476-482.

Schneider H.M. \& Lynch J.P. (2020) Should Root Plasticity Be a Crop Breeding Target? Frontiers in Plant Science 11, 1-16.

Schroder D. \& Kopke U. (2012) Faba bean (Vicia faba L.) intercropped with oil crops - a strategy to enhance rooting density and to optimize nitrogen use and grain production? Field Crops Research135 , 74-81.

Sebastian J., Yee M.-C., Goudinho Viana W., Rellan-Alvarez R., Feldman M., Priest H.D., ... Dinneny J.R. (2016) Grasses suppress shoot-borne roots to conserve water during drought. Proceedings of the National Academy of Sciences 113, 8861-8866. 
Sheahan M. \& Barrett C.B. (2017) Ten striking facts about agricultural input use in Sub-Saharan Africa. Food Policy $67,12-25$.

Shekoofa A. \& Sinclair T. (2018) Aquaporin activity to improve crop drought tolerance. Cells $7,123$.

Sinclair T.R. (2005) Theoretical analysis of soil and plant traits influencing daily plant water flux on drying soils. Agronomy Journal 97, 1148-1152.

Sinclair T.R., Devi J., Shekoofa A., Choudhary S., Sadok W., Vadez V., ... Rufty T. (2017) Limitedtranspiration response to high vapor pressure deficit in crop species. Plant Science 260 , 109-118.

Singh V., van Oosterom E.J., Jordan D.R., Messina C.D., Cooper M. \& Hammer G.L. (2010) Morphological and architectural development of root systems in sorghum and maize. Plant and Soil 333, 287-299.

Smith J., Pearce B.D. \& Wolfe M.S. (2013) Reconciling productivity with protection of the environment: Is temperate agroforestry the answer? Renewable Agriculture and Food Systems 28 , 80-92.

Strock C.F., Burridge J., Massas A.S.F., Beaver J., Beebe S., Camilo S.A., .. Lynch J.P. (2019) Seedling root architecture and its relationship with seed yield across diverse environments in Phaseolus vulgaris. Field Crops Research 237 , 53-64.

Strock C.F., Burridge J.D., Niemiec M.D., Brown K.M. \& Lynch J.P. (2020) Root metaxylem and architecture phenotypes integrate to regulate water use under drought stress. Plant Cell and Environment44, $49-67$.

Sultan B., Defrance D. \& Iizumi T. (2019) Evidence of crop production losses in West Africa due to historical global warming in two crop models. Scientific Reports 9 , 1-15.

Tan X., Shao D., Liu H., Yang F., Xiao C. \& Yang H. (2013) Effects of alternate wetting and drying irrigation on percolation and nitrogen leaching in paddy fields. Paddy and Water Environment11 , 381-395.

Tharanya M., Kholova J., Sivasakthi K., Seghal D., Hash C.T., Raj B., .. Vadez V. (2018) Quantitative trait loci (QTLs) for water use and crop production traits co-locate with major QTL for tolerance to water deficit in a fine-mapping population of pearl millet (Pennisetum glaucum L. R.Br.). Theoretical and Applied Genetics 131, 1509-1529.

Tsuji W., Inanaga S., Araki H., Morita S., An P. \& Sonobe K. (2005) Development and distribution of root system in two grain sorghum cultivars originated from Sudan under drought stress. Plant Production Science $8,553-562$.

Vadez V. (2014) Root hydraulics: The forgotten side of roots in drought adaptation. Field Crops Research $165,15-24$.

Vadez V., Kholova J., Medina S., Kakkera A. \& Anderberg H. (2014) Transpiration efficiency: New insights into an old story. Journal of Experimental Botany 65, 6141-6153.

Vadez V., Kholova J., Yadav R.S. \& Hash C.T. (2013) Small temporal differences in water uptake among varieties of pearl millet (Pennisetum glaucum (L.) R. Br.) are critical for grain yield under terminal drought. Plant and Soil 371, 447-462.

Vallino M., Fiorilli V. \& Bonfante P. (2014) Rice flooding negatively impacts root branching and arbuscular mycorrhizal colonization, but not fungal viability. Plant, Cell and Environment 37, 557-572.

Vieira R.F., Jochua C.N. \& Lynch J.P. (2007) Method for evaluation of root hairs of common bean genotypes. Pesquisa Agropecuaria Brasileira 42 , 1365-1368.

Wang Z., Zhang W., Beebout S.S., Zhang H., Liu L., Yang J. \& Zhang J. (2016) Grain yield, water and nitrogen use efficiencies of rice as influenced by irrigation regimes and their interaction with nitrogen rates. Field Crops Research 193, 54-69. 
Wortmann C.S., Kirkby R.A., Eledu C.A. \& Allen D.J. (1998) Atlas of common bean (Phaseolus vulgaris L.) production in Africa, CIAT publication. CIAT publication, Cali, Colombia.

Xue Y., Xia H., Christie P., Zhang Z., Li L. \& Tang C. (2016) Crop acquisition of phosphorus , iron and zinc from soil in cereal / legume intercropping systems : a critical review. 363-377.

Yan X., Liao H., Beebe S.E., Blair M.W. \& Lynch J.P. (2004) QTL mapping of root hair and acid exudation traits and their relationship to phosphorus uptake in common bean. Plant and Soil 265, 17-29.

York L.M., Carminati A., Mooney S.J., Ritz K. \& Bennett M.J. (2016) The holistic rhizosphere: Integrating zones, processes, and semantics in the soil influenced by roots. Journal of Experimental Botany67 , 36293643 .

York L.M., Nord E.A. \& Lynch J.P. (2013) Integration of root phenes for soil resource acquisition. Frontiers in Plant Science $4,1-15$.

Zhan A., Schneider H. \& Lynch J.P. (2015) Reduced Lateral Root Branching Density Improves Drought Tolerance in Maize. Plant physiology $168,1603-15$.

Zhang S., Guo X., Yun W., Xia Y., You Z. \& Rillig M.C. (2020) Arbuscular mycorrhiza contributes to the control of phosphorus loss in paddy fields. Plant and Soil 447,623-636.

Zhu J., Brown K.M. \& Lynch J.P. (2010) Root cortical aerenchyma improves the drought tolerance of maize (Zea mays L.). Plant, Cell and Environment 33, 740-749.

Zhu Y., Chen H., Fan J., Wang Y., Li Y., Chen J., ... Mundt C.C. (2000) Genetic diversity and disease control in rice. Nature406, 718-722.

Table 1. Summary of yield and income impact of $\mathrm{P}$ efficient varieties. Fixed costs of production mean twice as much yield has more than twice as much impact on income. Data from documents submitted to Mozambican Seed Release committee.

\begin{tabular}{lll}
\hline & Local variety & P-efficient variety \\
\hline Yield, no P fert & $737 \mathrm{~kg} / \mathrm{ha}$ & $1412 \mathrm{~kg} / \mathrm{ha}$ \\
Yield, with P fert & $1484 \mathrm{~kg} / \mathrm{ha}$ & $2844 \mathrm{~kg} / \mathrm{ha}$ \\
Income gain, no P fert & - & $249 \%$ \\
Income gain, with P fert & - & $148 \%$ \\
\hline
\end{tabular}



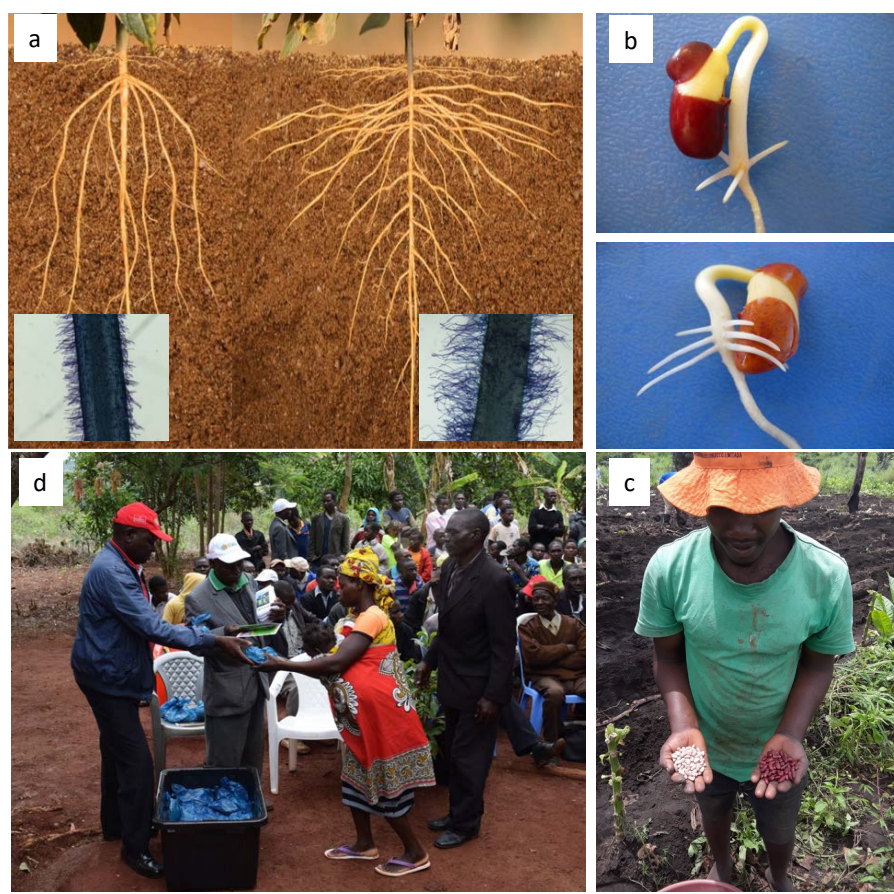

Figure 1. Greater basal root whorl number (BRWN) and longer and denser root hairs were selection targets to improve common bean production for small-holder farmers in Mozambique. a) Root on left shows a typical older variety with fewer basal roots and short root hairs. Image on right represent the improved varieties with more BRWN and longer root hairs. b) Bean seedling 4 days after imbibition showing 1 BRWN (top) and 3 BRWN (bottom). c) Improved beans in hands of smallholder farmers generating certified seed. d) Seed distribution in a Mozambican village as part of a pilot promotional campaign studied seed distribution, adoption and sharing. Image credits: a) still of movie sponsored by the CCRP and Mcknight Foundation (available at roots.psu.edu), photos of long and short root hairs courtesy of Anica Masas, b) courtesy of Katy Barlow, c) photo by Magalhaes Miguel, d) photo of seed distribution by James Burridge. 


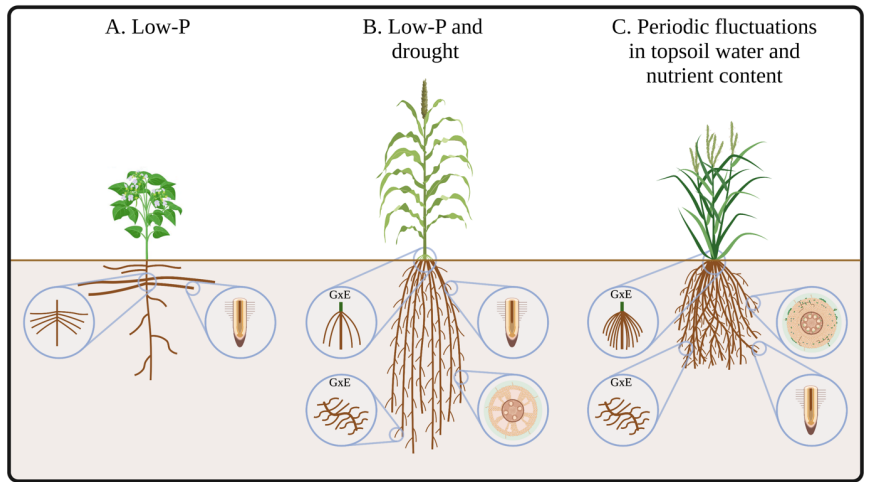

Figure 2. Root traits to optimize resource acquisition in common bean (left), sorghum (middle) and rice (right) when grown in low-input environments. For common bean grown in low-P soils, increased basal root whorl number and longer and denser root hairs were targeted to improve $\mathrm{P}$ acquisition efficiency. Proposed selection targets for sorghum grown in droughtprone regions with low-P soils in Sahelian Africa include greater root hair length and density for increased $P$ acquisition, combined with more aerenchyma for decreased carbon cost of root tissue and potentially reduced xylem vessel diameter for increased water use efficiency. Plasticity (GXE) in crown root number (reduced) and lateral root branching at depth (increased) are potential drought adaptive responses. In alternate wet and dry rice agroecosystems, proposed adaptive responses to periodic topsoil fluctuations in water and nutrient content include increased root hair development and plasticity in both crown root number and topsoil lateral root branching (increased upon dry-down), combined with greater beneficial interactions with arbuscular-mycorrhizal fungi. Figure was created with BioRender.com. Common bean drawing is from A. Bezvershenko. 